\title{
Possible mechanisms of rapid neurological deterioration and acute hydrocephalus in drug abusers
}

\author{
Ali Razmkon • Atefeh Bakhtazad
}

Received: 31 October 2008 / Accepted: 18 November 2008 / Published online: 27 January 2009

(C) Springer-Verlag 2009

Sir,

I read with interest the article by Mills et al. [1] describing opioid poisoning as a cause of severe cerebellitis in a child. We have observed a similar presentation in at least four individual patients suffering profound heroin addiction. These patients, albeit not children, but all around 18-20 years of age, presented with a sudden decrease in level of consciousness following episodes of heavy intravenous or inhalational heroin abuse.

Brain CT showed an invariable pattern of acute obstructive hydrocephalus in addition to generalized cerebellar oedema with resultant effacement of the cisterns and fourth ventricle. Unfortunately, brain MRI could not be performed in any of the patients because of their poor and rapidly deteriorating condition. Despite emergent medical therapy and external ventricular drainage, all of them died within 2 days. Cerebrospinal fluid studies were normal, and the presenting clinical condition could not be attributed to anything other than drug abuse.

This presentation is now becoming a nearly constant feature for intravenous drug abusers presenting with a sudden decreased level of consciousness, although in many of them except the above four, other causes of coma have been ruled in $[1,2]$. A few theories may explain this picture in such patients. Following opioid intoxication, respiratory compromise ensues, causing anoxic encephalopathy and

\footnotetext{
A. Razmkon $(\square) \cdot$ A. Bakhtazad

Department of Neurosurgery, Shiraz Faculty of Medicine, Nemazee Hospital, Shiraz University of Medical Sciences, P.O. Box 71455-166, Shiraz, Iran

e-mail: ali.razmkon@gmail.com
}

diffuse oedematous swelling of the brain. A form of toxic leukoencephalopathy causing cerebellar oedema and hydrocephalus has also been described resulting from inhalation of heroin, and also from methadone poisoning $[1,3]$. In a case report by Derlon et al. [4], traumatic compression and occlusion of the left vertebral artery at the level of $\mathrm{C} 2$ during an alcoholic coma caused oedematous cerebellar infarction and hydrocephalus. In a further case report of central nervous system mucormycosis, Woods and Hanna [5] suggested that drug abuse should be included in the differential diagnosis in a patient presenting with a rapid deterioration in neurological status due to acute hydrocephalus. Acute hydrocephalus and cerebellar oedema has also been reported following carbon monoxide poisoning [6].

In conclusion, it is crucial to exclude opioid abuse in every individual with rapid neurological deterioration due to cerebellar oedema and acute hydrocephalus.

\section{References}

1. Mills F, MacLennan SC, Devile CJ et al (2008) Severe cerebellitis following methadone poisoning. Pediatr Radiol 38:227-229

2. Melaiki BT, Thabet F, Anjum SB et al (2007) Acute cerebellitis with hydrocephalus and brainstem compression. Arch Dis Child 92:38

3. Anselmo M, Campos Rainho A, do Carmo Vale M et al (2006) Methadone intoxication in a child: toxic encephalopathy? J Child Neurol 21:618-620

4. Derlon JM, Charbonneau P, Théron J et al (1983) Edematous cerebellar infarction in the young subject. Neurochirurgie 29:423428

5. Woods KF, Hanna BJ (1986) Brain stem mucormycosis in a narcotic addict with eventual recovery. Am J Med 80:126-128

6. So GM, Kosofsky BE, Southern JF (1997) Acute hydrocephalus following carbon monoxide poisoning. Pediatr Neurol 17:270-273 